Dieses Dokument ist eine Zweitveröffentlichung (Postprint) / This is a self-archiving document (postprint):

Prathap Valluru, Janakiram Karlapudi, Karsten Menzel, Teemu Mätäsniemi, Jari Shemeika

A Semantic data model to represent building material data in AEC collaborative workflows

Erstveröffentlichung in / First published in:

Boosting Collaborative Networks 4.0. PRO-VE 2020, Valencia, 2020.

SpringerProfessional, S. 133-142. ISBN 978-3-030-62412-5

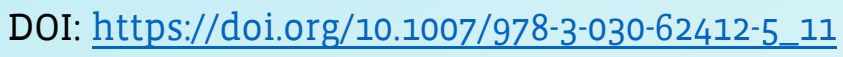

Diese Version ist verfügbar / This version is available on:

https://nbn-resolving.org/urn:nbn:de:bsz:14-qucosa2-735370 


\title{
A Semantic data model to represent building material data in AEC collaborative workflows
}

\author{
Prathap Valluru ${ }^{1}$, Janakiram Karlapudi ${ }^{1}$, Karsten Menzel ${ }^{1}$, \\ Teemu Mätäsniemi², Jari Shemeika \\ ${ }^{1}$ Institute of Construction Informatics, Technische Universität Dresden, \\ Dresden, Germany \\ Prathap.Valluru@tu-dresden.de \\ \{Janakiram.Karlapudi, Karsten.Menzel1\}@tu-dresden.de \\ ${ }^{2}$ VTT Technical Research Centre of Finland Ltd, Espoo \\ \{Teemu.Matasniemi, Jari.Shemeikka\}@vtt.fi
}

\begin{abstract}
The specification of building material is required in multiple phases of engineering and construction projects towards holistic BIM implementations. Building material information plays a vital role in design decisions by enabling different simulation processes, such as energy, acoustic, lighting, etc. Utilization and sharing of building material information between stakeholders are some of the major influencing factors on the practical implementation of the BIM process. Different meta-data schemas (e.g. IFC) are usually available to represent and share material information amongst partners involved in a construction project. However, these schemas have their own constraints to enable efficient data sharing amongst stakeholders. This paper explains these constraints and proposes a methodological approach for the representation of material data using semantic web concepts aiming to support the sharing of BIM data and interoperability enhancements in collaboration workflows. As a result, the DICBM (https://w3id.org/digitalconstruction/BuildingMaterials) ontology was developed which improves the management of building material information in the BIM-based collaboration process.
\end{abstract}

Keywords: BIM, Building Material Ontology, IFC, Linked Data, Data sharing.

\section{Introduction and Background}

Over the last two decades, the advancement in Information and Communication Technology (ICT) improved the processing and management of information in the Architecture, Engineering, and Construction (AEC) industries, specifically by adopting Building Information Modeling (BIM) concepts. However, the identification of critical information, its management along with the efficient collaboration, and communication between the participants in the project are some barriers in the traditional building construction process [1, 2]. Research work by L.M. Camarinha-Matos et al (2007) discussed that Collaborative Networks (CNs) can play a key role in effective knowledge management, and collaboration between teams involved in a project [3]. The different 
classification of $\mathrm{CNs}$ are well described e.g. in research work carried by CamarinhaMatos et al. in (2005), (2010) [4, 5]. The usage of CNs spread to several industries and gained benefits from it.

In recent years, the $\mathrm{AEC}$ industry got motivated to use CNs in the project life cycle. As a result, numerous commercial collaboration platforms became available, e.g. BIMCollab $^{1}$, BIMcloud ${ }^{2}, \mathrm{~A} 360^{3}$, just to name a few. However, most of these tools utilize proprietary formats for data representation and thus lack in effective integration of Common Data Environments (CDE) [6]. Also, there are still challenges in terms of information sharing and management between the actors in heterogeneous environments [7]. The desire to overcome these challenges gained interest in the BIM4EEB $^{4}$ EU project. The project aims to develop (i) a BIM collaborative environment called BIM Management System (BIMMS ${ }^{5}$ ) with an integrated CDE and web applications and (ii) a linked building data modeling and sharing framework for interoperable communication and data exchange amongst all actors involved in the renovation process. The work presented in this paper focuses on the latter topic namely at ontology models for building material information.

To specify the scope of collaboration activities in AEC researchers of the BIM4EEB project identified approximately 23 stakeholders and close to 200 distinct collaboration scenarios undertaken by the stakeholders in six life cycle stages of a building under renovation [8]. Such a complex collaboration network needs access to all information about the building for each specific activity handled by the stakeholders in flexible, interoperable formats. Information about building materials is one of the important aspects to manage a building holistically and in a sustainable way over all phases of its building life cycle. The assignment of material specifications to building elements and sharing these details between stakeholders involved is a decisive task and influences a project to a great extent. This information associated with different layers of building elements is necessary to perform energy, acoustic, lighting, etc. simulations at different stages of the project. Development and analysis of engineering models of a building from its early stages onwards enable performance evaluations and support informed design decisions based on optimization [9-11]. The efficient data transfer from BIM to analytical models considerably increases the efficiency and reduces the inconsistencies, efforts, and time [12]. Based on previous research on the persistent challenges for data sharing [9], [13-16], this paper introduces a semantic data model to represent building material information in the conversion process of BIM models to analytical models (e.g. Building Energy Model (BEM), Structural Model, MEP Model, etc.). Also, it explores different complexities in present data schemas and explains different constraints imposed by this.

\footnotetext{
${ }^{1}$ https://www.bimcollab.com/

$2 \mathrm{https} / / /$ graphisoft.com/support/system_requirements/AC21/bimcloud/

${ }^{3} \mathrm{https}: / /$ a360.autodesk.com/

${ }^{4}$ https://www.bim4eeb-project.eu/

${ }^{5}$ https://bim4eeb.oneteam.it/BIMMS/Default.aspx\#
} 


\subsection{Building Information Modeling for collaboration}

Building Information Modeling (BIM) has gained major attention in the AEC industry. The acronym BIM has several definitions developed by the scientific community [17$18]$ and is supported by multiple standards [19-21]. However, the common idea of BIM is to represent built assets in a digital format based on reliable, coordinated, and appropriate information throughout the building life cycle. Coordinated information models generated from the BIM process can enable stakeholders to use project information consistently and reliably over different project scopes [22].

The development of the schema of the Industry Foundation Classes (IFC), standardized by ISO 16739 [23], became a major openBIM data model. The IFC allows various actors involved in the project life cycle to represent BIM data uniformly. Apart from the development of BIM models' geometry, the effective usage of it across the different disciplines is still a challenge. The major reason is due to a lack of a collaborative environment and interoperability between the heterogeneous BIM tools. The desire to overcome these constraints gained attention to develop BIM-based collaborative spaces called Common Data Environment (CDE) and the use of semantic web technologies.

In such collaborative systems, IFC has been used for model-based collaboration [24]. However, recent research $[25,26]$ comprehensively explains the constraints of the IFC schema corresponding to extendibility, querying, reasoning, and interoperability. Most of these limitations can be overcome by adopting semantic web technologies.

\subsection{Information management in AEC using semantic web technologies}

The term Semantic Web (SW) was introduced by Tim Berners-Lee in (2001) [27]. The introduction of SW standards allows us to publish data on the web but this data was never linked. By considering this problem, Tim Berners-Lee introduced the Linked Data $^{6}$ concept in 2006, to link information across domains. Apart from the technical evaluation of Semantic Web and Linked Data, the need has increased for shared semantics and a web of data and information derived from it [28].

For example, collaborative networks "consist of a variety of entities that are largely autonomous, geographically distributed, and heterogeneous in terms of their operating environment" [29]. Such systems require the adoption of ontologies for the integration of data sets and knowledge representation.

Early research efforts [30-33] using ontologies in CNs, created an interest in the AEC industry to use ontologies. Meanwhile, several research efforts [34-38] were carried out in the Architecture, Engineering, Construction, and Facilities Management (AEC/FM) sectors to improve the availability of building data by using Semantic Web technologies and Linked Data approach. The main goal of using SW technologies and the Linked Data approach is to achieve data universality and interlinking of data from different sources. Additionally, the concept of the semantic web enables greater extensibility of information and knowledge modeling according to the domain requirements.

\footnotetext{
${ }^{6}$ https://www.w3.org/DesignIssues/LinkedData
} 


\section{DICBM: Digital Construction Building Material Ontology}

\subsection{Building Material Data in IFC}

The open meta data model IFC is considered as a reference model for material data. In the IFC-based, openBIM meta-data model entities are related to their resources using the concept of objectified relationships. Material specifications of building elements are defined as a resource in the IFC- schema. They are related to respective building elements through the objectified relationship called 'IfcRelAssociatesMaterial'. Research from [34] proposes a translation of the EXPRESS schema to ifcOWL, i.e. an ontological representation of IFC aiming to achieve improved functionalities and benefitting from linked data concepts. In this case, modeling of material and assignment to building elements uses a similar method, but modeling languages are different. Limitations in terms of extendibility, reasoning, vocabulary, and inference are distinct [39].

To address these issues, various approaches were proposed to reduce these limitations of ifcOWL and to simplify the ontological representation. Some of them are simpleBIM [36], ifcWOD [39], and BimSPARQL [40]. The above-introduced approaches (ifcWOD, simpleBIM, BimSPARQL) have the potential to improve the execution of queries. But for real industrial applications, it is necessary to go with a more generic approach using modular ontologies and RDF graphs [26]. The Digital Construction Building Material (DICBM) ontology proposed in this paper is a modular ontology and represents material data effectively.

\subsection{Overview of the building material ontology}

DICBM contains the required set of terminological axioms and vocabulary to represent construction details and material data along with the analytical parameters for building elements.

Fig. 1 provides an overview of classes and object properties defined in DICBM. The prefix and namespace used to refer the material ontology shown below.

(a)PREFIX dicbm: <https://w3id.org/digitalconstruction/BuildingMaterials\#>.

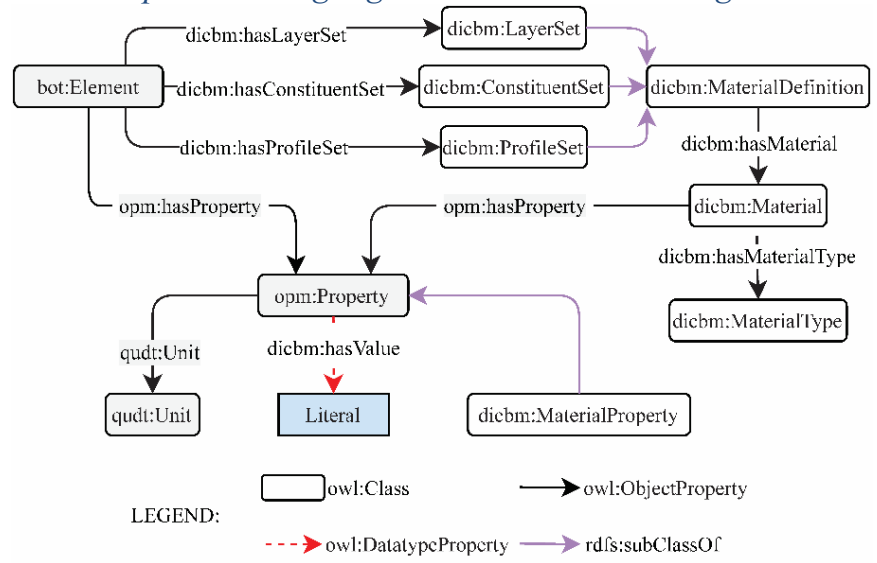

Fig. 1. Overview of Building Material Ontology 


\subsection{Integration of external ontology concepts and roles}

The concept of integration of external ontologies is a process of adoption of other ontologies or ontology concepts within the development of new ontologies [41]. In DICBM, this integration process is carried out for the representation of material definition concepts, properties, and its units. Some information about objects and parameters are already modeled in existing AEC-domain specific or generic ontologies.

Instead of redefining these concepts in DICBM, the classes and object properties from the existing ontologies BOT [35], OPM [37], and QUDT $^{7}$ are adopted. This will also allow for alignment between different ontologies, domains and enable extended modelling capabilities and usage of DICBM. The Class bot:Element is defined in the DICBM ontology to represent a different kind of building element designed and managed by stakeholders from different engineering disciplines. Similarly, the class bot:Zone is used to represent the spatial elements designed by architects, used by tenants, and managed by the owners of the building. The Object Property (OP) bot:adjacentElement [35] is used to link the spatial elements with an element that shares part of its boundary.

The Class opm:Property [37] is defined to describe the properties of an object in DICBM. The object property opm:hasProperty [37] is used in DICBM to maintain properties of the object. This property is treated as the main object property and all other defined properties in DICBM are considered as sub-properties of opm:hasProperty. Thus, descriptive information which satisfies the information requirements of different collaborators can be easily linked to building elements and zones. Examples are technical properties, prices, comfort parameters, etc. The class qudt:Unit is integrated with DICBM to represent the unit for the material properties and object properties. The OP qudt:Unit is used to enable a relationship between qudt:Unit and the properties of an element.

\subsection{Material Definition}

The material data needs to be assigned to building elements on different levels [23]. For example, in IFC material properties are assigned to layer, profile, and constituent. This feature is defined explicitly by grouping using the concept called MaterialDefinition in DICBM. A concept to represent material related information that has material related properties is dicbm:MaterialDefinition. Material Definition closely represents the entity IfcMaterialDefinition in IFC. The dicbm:MaterialDefinition has six subclasses, which are dicbm:LayerSet, dicbm:ConstituentSet, dicbm:ProfileSet, dicbm:Layer, dicbm:Constituent, and dicbm:Profile.

Building elements (e.g. wall, roof, etc.) may consist of one or more layers. These layers' information for a specific building element is grouped using the LayerSet concept of the IFC schema. This grouping mechanism automatically separates the repetitive definition of similar layer information in different parts. Furthermore, the concept of LayerSet enables the definition of one single set for a distinct layer to $n$

\footnotetext{
${ }^{7} \mathrm{http}: / /$ www.qudt.org/2.1/catalog/qudt-catalog.html
} 
number of walls (or other elements) based on its category. Additionally, the relative positioning of individual layers can be expressed. The object property dicbm:hasLayerSet is used to link the element with its layer set. The range of the Object Property (OP) dicbm:hasLayerSet is defined explicitly as dicbm:LayerSet.

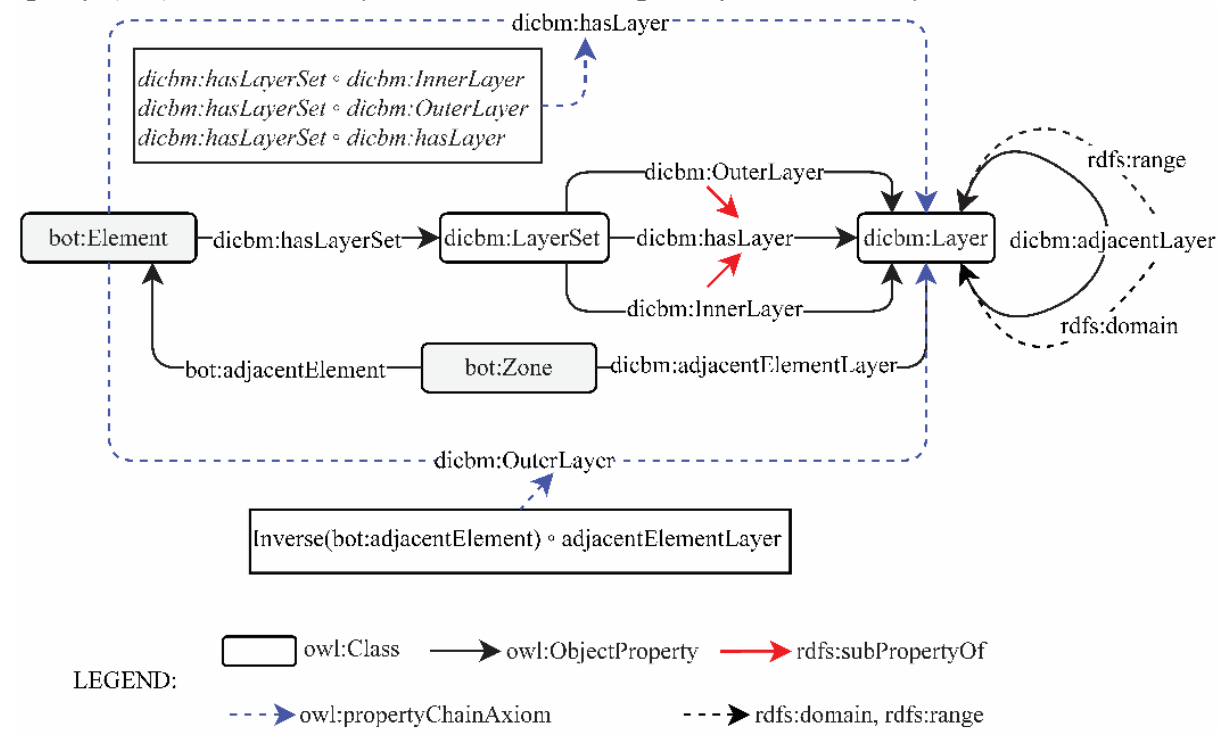

Fig. 2. Schematic representation of layer association with its element

The dicbm:Layer is the concept to represent a layer of an element. A layer may be inner or outer layer of a building element based on its placement in the structure. To distinguish between the inner and outer layer of the element, OP dicbm:InnerLayer, dicbm:OuterLayer is used to link the source nodes of the element, layer set, and layer. The property chain axioms are defined for dicbm:hasLayer to assign the layer to the element. The range of the dicbm:hasLayer is dicbm:Layer. The property axiom of dicbm:hasLayer is shown in the Fig. 2.

The order and position of layers in the building element is also considered in DICBM. The role called adjacent layer is introduced, which relates layers to each other. This role was inspired by an object property adjacent element in the BOT [35] ontology. Fig. 2 shows the link between (building) elements, layer set, and constituent layers.

The OP dicbm:adjacentLayer is a symmetric property. To define the layer arrangement explicitly, layer position is described by linking with its adjacent elements. The OP dicbm:adjacentElementLayer links topological elements to the element layer sharing its boundary. The outer layer of the wall is explicitly defined by using the property chain axioms. The dicbm:OuterLayer is the OP to link a building element to its outer layer.

\subsection{Material, Material Type, and Material Property}

The dicbm:Material is a concept to represent the material. Material type, associated products, properties exist in the context of material data. Material is linked with its 
objects using the role dicbm:hasMaterial. For example, the material of the layer is described as dicbm:hasMaterial(dicbm:Layer, dicbm:Material) by using functional syntax. A dicbm:hasMaterial is an owl:ObjectProperty and range is the concept dicbm:Material.

Material property is a characteristic of a material. It holds the data related to different properties of a material. A class dicbm:MaterialProperty is defined in the DICBM ontology and it is considered as a subclass of opm:Property. This concept represents a characteristic of a material.

\subsection{Data Properties in DICBM}

Data property dicbm:Name is modeled in DICBM to represent the name of objects and material properties. The dicbm:hasRerence is a data property used to link property with its source. Fig. 3 shows the data properties defined in the DICBM ontology. Value describes the simple, defined, or measured quantity of the property of an object.

Stakeholders involved in data acquisition (e.g. surveyors) create measured values and model creation before a renovation starts. Defined values are used by stakeholders from the engineering disciplines. The definition is the outcome of dimensioning activities for which simulations are heavily used. Defined values are used by engineers employed by construction companies. Estimated values are used by quantity surveyors before the procurement activities will be completed.

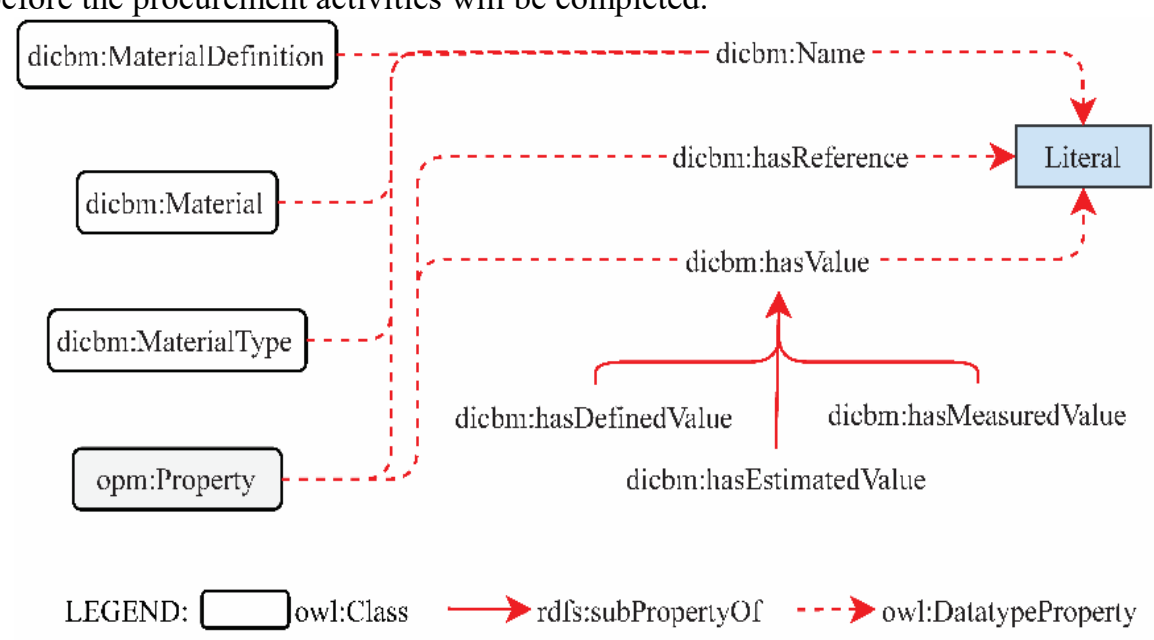

Fig. 3. Data properties in the ontology schema

As one can see, the proposed ontology supports effective data sharing in collaborative networks in the AEC-domain during renovation activities, since property values can be clearly distinguished according to authenticated sources, calculated values, and values from measurement processes. 


\section{Conclusions}

Building material data are important information for the performance evaluation of buildings, including energy simulations, environmental impact studies, structural analysis, or the dimensioning of building elements [42]. Numerous stakeholders must share their expertise during this evaluation process since it is necessary to evaluate building performance holistically, i.e. from a societal, economic, and ecological perspective. In order to support seamless, effective information sharing between different digital building models created by different experts, it is necessary to capture material information of building elements in a generic, easily accessible, transparent, and flexible way. Re-formatting of data, labour-intensive search, and selection activities must be eliminated.

Thus, the Linked Data concept in combination with semantic modelling is one possible solution to address these requirements. Therefore, the authors presented in this paper a semantic model that can capture building material specifications and link those to building elements (layers) and additionally link building elements to zones, which are finally occupied by tenants. The material information data specified and stored using DICBM can be linked to different models within a Common Data Environment. DICBM can be used in combination with a further product, quantity, and propertyrelated information. Therefore, the authors argue that the proposed approach has the potential to become an enabling technology to support collaborative networks in the AEC\&FM-sector.

Acknowledgments. This research is carried out as a part of the BIM4EEB project (BIM based fast toolkit for the Efficient rEnovation of Buildings). The BIM4EEB project is supported and funded by the European Union's Horizon 2020 research and innovation program. We would like to show our gratitude to the European Commission for the support of the BIM4EEB project. Finally, we would like to thank all partners in the BIM4EEB project for their valuable inputs.

\section{References}

1. Scherer R. J., Katranuschkov P.: BIMification: How to create and use BIM for retrofitting. Advanced Engineering Informatics. vol. 38, pp. 54--66 (2018).

2. Jiang J., Chen J.: Contractual Collaboration Systems of Mega Complex Construction Project Organizations. In: ICCREM 2014: Smart Construction and Management in the Context of New Technology (2014).

3. Camarinha-Matos L. M., Afsarmanesh H.: Collaborative networks in industry and services: research scope and challenges. IFAC Proceedings Volumes, vol. 40, pp. $33--42$ (2007).

4. Camarinha-Matos L. M., Afsarmanesh H.: Collaborative networks: Value creation in a knowledge society. In: Knowledge Enterprise: Intelligent Strategies in Product Design, Manufacturing, and Management, Springer, New Challenges (2006).

5. Camarinha-Matos L. M., Afsarmanesh H.: Classes of Collaborative Networks. In: IT Outsourcing: Concepts, Methodologies, Tools, and Applications. IGI Global. pp. 364--370 (2009). 
6. Alreshidi E., Mourshed M., Rezgui Y.: Factors for effective BIM governance. Journal of Building Engineering. pp. 89--101 (2017).

7. Cristóvão S., Pereira C.: Sharing through Collaborative Spaces: Enhancing Collaborative Networks Interoperability. In: Camarinha-Matos L. M., Afsarmanesh H. (eds.). PROVE2014. IFIP AICT, vol. 434, pp. 481--488 (2014).

8. BIM4EEB: D2.1 Definition of relevant activities and involved stakeholders in actual and efficient renovation processes (2019). https://www.bim4eeb-project.eu/reports.html.

9. Karlapudi J., Shetty, S.: A methodology to determine and classify data sharing requirements between OpenBIM models and energy simulation models. In: 31. Forum Bauinformatik, Berlin (2019).

10. Yin H., Stack P., Menzel, K.: Decision support for building renovation strategies. In: Proceedings of the ASCE-Congress in Computing in Civil Engineering, pp. 834-841 (2011).

11. Cahill B., Menzel K., Flynn D.: BIM as a centre piece for Optimised Building Operation. In: eWork and eBusiness in Architecture, Engineering and Construction, pp. 549 - 555 (2012).

12. Keller M., Menzel K., Scherer R. J.: Toward a Meta-Model for Collaborative Construction Project Management. In: Proceedings of the Working Conference on Virtual Enterprises, pp. 361-368 (2005).

13. Lilis G. N., Giannakis G. I., Rovas D. V.: Automatic generation of second-level space boundary topology from IFC geometry inputs. Automation in Construction. pp. 108-124 (2017).

14. Keller M., Katranuschkov P., Menzel K.: Modelling collaborative processes for Virtual Organisations in the building industry. In: eWork and eBusiness in Architecture, Engineering and Construction, pp. 417--431, Balkema Publishers (2004).

15. Keller M., Scherer R.J., Menzel K., Theling T.: Support of collaborative business process networks in AEC. In: IT-Con Journal: vol. 11, pp. 449--465 (2006).

16. Karlapudi J., Menzel K.: Analysis on automatic generation of BEPS models from BIM model. In proceedings of BauSIM 2020, 8th conference of IBPSA, Austria (2020).

17. Chuck E., Paul T., Rafael S., Kathleen L.: BIM handbook: A guide to building information modeling for owners, managers, designers, engineers and contractors. John Wiley \& Sons (2011).

18. Bilal S.: Building information modelling framework: A research and delivery foundation for industry. Automation in construction, vol. 14(1), pp. 15--32 (2009).

19. BSI.: PAS 1192-2:2013: Specification for information management for the capital/delivery phase of construction projects using building information modelling. BSI Standards Limited (2013).

20. ISO.: ISO 29481-1: 2016 (E): Building Information Modeling-Information Delivery Manual-Part 1: Methodology and Format. ISO, Geneva, Switzerland (2016).

21. ISO.: EN ISO 19650-1:2018: Organization and digitization of information about, BSI Standards Limited (2018).

22. Nityantoro E., Scherer R. J.: Ontology supported recombination of multi-models. In: Camarinha-Matos L. M., Scherer R. J (eds.). PRO-VE2013. IFIP AICT, vol. 408, pp. 257-264 (2013).

23. ISO.: ISO 16739: 2013--Industry Foundation Classes (IFC) for data sharing in the construction and facility management industries (2013).

24. Preidel C., Borrmann A., Oberender C., Tretheway M.: Seamless Integration of Common Data Environment Access into BIM (2015).

25. Beetz J., Van Leeuwen J., De Vries B.: IfcOWL: A case of transforming EXPRESS schemas into ontologies. Ai Edam. vol. 23, pp. 89--101 (2009). 
26. Bonduel M., Oraskari J., Pauwels P., Vergauwen M., Klein R.: The IFC to linked building data converter-current status. In: 6th Linked Data in Architecture and Construction Workshop, vol. 2159, pp. 34--43 (2018).

27. Berners-Lee T., Hendler J., Lassila O.: The semantic web. Scientific american, pp. 34--43 (2001).

28. Shadbolt N., Berners-Lee T., Hall W.: The semantic web revisited. IEEE intelligent systems, vol. 21, no. 3, pp. 96--101 (2006)

29. Camarinha-Matos L. M., Afsarmanesh H.: Collaborative networks: a new scientific. Journal of intelligent manufacturing. vol. 16, pp. 439--452 (2005).

30. Spoladore D.: Ontology-based decision support systems for health data management to support collaboration in ambient assisted living and work reintegration. In: L.M. CamarinhaMatos et al. (eds.): PRO-VE 2017, IFIP AICT 506, pp. 341--352 (2017).

31. Aris P., Jakob Axel Bejbro A., Laumann Kjær L., Anja M., McAloone T. C.: Building an Ontology of Product/Service-Systems: using a maritime case study to elicit classifications and characteristics. In: Camarinha-Matos L. M., Afsarmanesh H. (eds.). PRO-VE2014. IFIP AICT, vol. 434, pp. 119--126, (2014).

32. Antonelli D., Bruno G.: Ontology-based framework to design a collaborative human-robotic workcell. In: L.M. Camarinha-Matos et al. (eds.): PRO-VE 2017, IFIP AICT 506, pp. $167-$ -174 (2017).

33. Rachman A., Ratnayake R. C.: Ontology-based semantic modeling for automated identification of damage mechanisms in process plants. In: L. M. Camarinha-Matos et al. (Eds.): PRO-VE 2018, IFIP AICT 534, pp. 457-466, (2018).

34. Pauwels P., Terkaj W.: EXPRESS to OWL for construction industry: Towards a recommendable and usable ifcOWL ontology. Automation in Construction. vol. 63, pp. 100-133 (2016).

35. Rasmussen M. H., Pauwels P., Lefrançois M., Schneider G. F.: Building Topology Ontology. W3C Draft Community Group Report (2019).

36. Pauwels P., Roxin A.: SimpleBIM: From full ifcOWL graphs to simplified building graphs. In: Proceedings of the 11th ECPPM, pp. 11--18 (2016).

37. Rasmussen M. H., Lefrançois M., Pauwels P., Hviid C. A., Karlshøj J.: Managing interrelated project information in AEC Knowledge Graphs. Automation in Construction. vol. 108, pp. 102956 (2019).

38. Karlapudi J., Menzel K., Törmä S., Hryshchenko A., Valluru P.: Enhancement of BIM Data Representation in Product-Process Modelling for Building Renovation. In proceedings of $17^{\text {th }}$ IFIP International Conference on Product Lifecycle Management. 5-8 July. Rapperswil, Switzerland (2020).

39. De Farias T. M., Roxin A., Nicolle C.: IfcWoD, semantically adapting IFC model relations into OWL properties. (2015).

40. Zhang C., Beetz J., de Vries B.: BimSPARQL: Domain-specific functional SPARQL extensions for querying RDF building data. Semantic Web, pp. 1--27 (2018).

41. Sofia P. H., Asuncion G.-P., Joao P. M.: Some Issues on Ontology Integration. In: Proceedings of the IJCAI (1999).

42. Ahmed A., Menzel K., Ploennigs J., Cahill B.: Aspects of multi-dimensional building performance data management. In: Proceeding of EG-ICE, TU Berlin, Germany (2009) 